occupies two and a half pages and three references cannot do them justice. Nevertheless teachers will applaud the book for many references, some so recent that they were probably added in proof, and for the author's habit of quoting major references at the end of sections and of the book. Students lucky enough to borrow the book, for sadly few can afford personal copies, will find it an excellent "thoughtsaving" source for essays.

However, students grow into practitioners of plant pathology and they will often find the six hundred pages contain disappointingly brief answers to their inquiries or conclude their special interests have too little attention. Is it right that any comprehensive book on the principles of plant pathology should dismiss viruses and mycoplasmata with thirty-six pages and an apology? Although "root diseases" are mentioned often, the chapter devoted to them is only a third of that on viruses and about half that on "non-parasitic agents". The chapters dealing with infection, attack and defence mechanisms are more satisfying and the author is to be complimented on recognizing both that there is an epidemiology of root diseases and the importance of pathogen and host carry-over in starting epidemics. The latter theme is emphasized again through disease control by sanitation and cultural practices. Other chapters contain good summaries of existing knowledge on dispersal, forecasting and assessing diseases or controlling them by fungicides, resistance, quarantine and so on. However, I am still waiting for the book that not only describes the principles of plant pathology as an academic subject, but also stresses how disease control must be fitted into changing agricultural systems and show benefits greater than its cost.

J. M. HIRST

\section{Chromatophores}

Chromatophores and Color Change: The Comparative Physiology of Animal Pigmentation. By Joseph T. Bagnara and Mac E. Hadley. Pp. xvi+202. (Prentice-Hall: Englewood Cliffs, New Jersey, January 1973.) $£ 6$.

NotwrthstandiNG the jacket's claim, "a balanced review of all facets", there is a strong bias towards the authors' own fields of research, as they are first to emphasize. Some readers will question whether so strong a bias is justified under the very broad title. Certainly the authors' research fields-the microanatomy and development of chromatophores, and their behaviour as effector organs in vertebrates - have been among the most progressive in recent years and this series of books is intended for specialists as well as for students.

The relevant chapters account for $80 \%$ of the whole text $(85 \%$ if the introductory and concluding chapters are excluded) and their share of the references is $78 \%(80 \%)$. They constitute admirable reviews but the remainder seem too sketchy even for junior students. Chapter 3 on the biochemistry of the pigments seems particularly light, and also adrift, no doubt because the "visual-effect" functions of the integumental chromes depend essentially on biophysical properties and mechanisms, chemical properties being largely irrelevant.

It should be re-emphasized that the structure and development of chromatophores and their organelles are well reviewed, with excellent illustrations and that the hormonal and nervous controls of vertebrate chromatophores are very critically discussed: some may feel that the authors are hypercritical concerning the significance of melatonin. There is a generous bibliography, mainly of recent references, in line with the aims of the series, but what a pity such a long list is not arranged alphabetically, particularly as there is no author index.

In spite of the weight of the authors' summing up, a number of leading questions must be considered still sub-judice. Many will wear Sir Lancelot's favours in the tournament of hormonal control and the albedo school will question whether a pineal-incident light response can be independent of the pituitarybackground response.

A. E. NeEdham

\section{Nobel Biology}

Nobel Lectures, Physiology or Medicine. 1963-1970, including Presentation Speeches and Laureates' Biographies. Pp. $x+273$. (Elsevier: Amsterdam, London and New York, 1973.) Dfl. 110; US\$ 34.50 .

THESE Nobel Lectures are an enjoyable if expensive way of keeping up with the major advances of biology and medical science. Needless to say, the authors are an all-star cast-(in order of appearance) Eccles, Hodgkin, Huxley; Bloch and Lynen; Jacob, Lwoff and Monod; Rous and Huggins; Granit, Hartline and Wald; Holley, Khorana and Nirenberg; Delbrück, Hershey and Luria; Axelrod, von Euler and Katz.

The lectures are about equally divided between molecular biology in its now accepted sense, expounded by many of its founders, and neurosensory physiology, a subject that was deeply molecular long before many of the disciplines now eager to be so described. The lectures are remarkably good reading because the authors have obviously taken considerable pains with them. The citation or presentation speeches have also been very carefully prepared and add greatly to the value of the volume. These Nobel Lectures could be really useful reading for students of medicine or life sciences from whom future laureates must be recruited. It is a pity that some great Foundation at its wits' end to know how to spend its money does not subsidize their publication in paperback, so putting the lectures within the means of those who would benefit most by reading them.

P. B. MEDAWAR

\title{
Marine Fauna
}

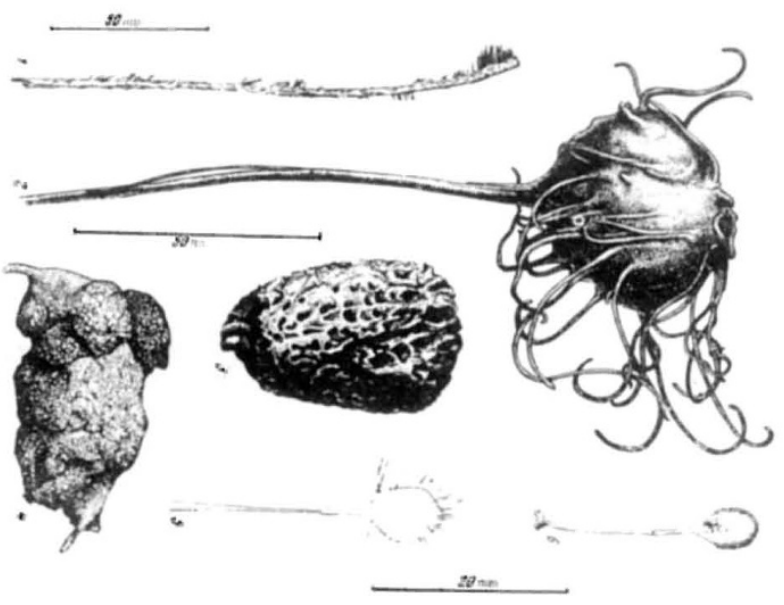

Inhabitants of the Kurile-Kamchatka Trench, as revealed in the thirty-ninth cruise of the Vityaz: one of the drawings from Fauna of the Kurile-Kamchatka Trench and its Environment, edited by V. G. Bogorov and distributed for the Academy of Sciences of the USSR and the Israel Program for Scientific Translations by Wiley (Chichester, 1973). 